\title{
Оценка устойчивости антоцианов, ацилированных малоновой кислотой
}

\author{
Дейнека В.И., Сидоров А.Н., До Ван Куи, Дейнека Л.А. \\ ФГАОУ ВПО «Белгородский государственный национальный исследовательский университет», \\ Белгород
}

Поступила в редакцию 28.04.2017 г.

В работе методом обращенно-фазовой ВЭЖХ оценена стабильность трех производных антоцианов из экстракта оберток пурпурной кукурузы, ацилированных малоновой кислотой: цианидин-3(3",6"-дималонилглюкозида), цианидин-3-(6"-малонилглюкозида), цианидин-3-(3"малонилглюкозида) относительно удаления ацилирующей кислоты. Время, необходимое для гидролиза половины ацилированного антоциана в комнатных условиях составляет 30, 45 и 80 суток для указанных выше соединений. При хранении в бытовом холодильнике $\left(4^{\circ} \mathrm{C}\right)$ скорость гидролиза снижается примерно в 5 раз.

Ключевые слова: ВЭЖХ, ацилированные производные цианидин-3-глюкозида, малоновая кислота, гидролиз, устойчивость.

\section{Estimation of stability of anthocyanins acylated with malonic acid}

\author{
Deineka V.I., Sidorov A.N., Do Van Quy, Deineka L.A. \\ Belgorod National Research University, Belgorod
}

In the paper the method of reversed-phase HPLC was used to evaluate the stability of three derivatives of anthocyanins from the extract of purple corn husk, acylated by malonic acid: cyanidin-3-(3",6"dimalonylglucoside), cyanidin-3-(6"-malonylglucoside), cyanidin-3-(3"-malonylglucoside) regarding the loss of malonic acid moiety. The purified compounds were obtained by semi-preparative reversed phase HPLC; two series of solutions were stored at room temperature and in refrigerator $\left(4^{\circ} \mathrm{C}\right)$. The solutions were periodically analyzed by HPLC, while the three above mentioned compounds with addition of cyanidin-3-glucoside were separated to estimate simultaneously the concentrations, believed to be proportional to peak areas. The data for all the cases fit first order reaction for anthocyanins concentration in spite of not careful temperature control for room temperature storage. The rate of anthocyanins hydrolysis dropped in the series: cyanidin-3(3",6"-dimalonylglucoside), cyanidin-3-(6"-malonylglucoside), cyanidin-3-(3"-malonylglucoside), while the sum of rate constants for last two substances is closed to the rate constant for the first compound. The withdrawal of the acid moiety form position 6" happened easily then from position 3". So the ratio of acylated and non acylated anthocyanins may be changed at not properly storage. It was established that the time required for hydrolysis of half of the initial acylated anthocyanin at room temperature is 30,45 and 80 days for compounds listed above, respectively. In the case the storage in refrigerator $\left(+4^{\circ} \mathrm{C}\right)$ the rate of hydrolysis is reduced by about 5 times.

Keywords: HPLC, acylated derivatives of cyanidin-3-glucoside, malonic acid, hydrolysis, stability.

\section{Введение}

Среди множества видов антоцианов наиболее устойчивыми считаются соединения, ацилированные некоторыми карбоновыми кислотами [1-3]. Как и все водо- 
растворимые полифенолы антоцианы обладают антиоксидантной активностью, т.е. должны достаточно легко окисляться в растворах. Поэтому не удивительно, что в поисковой системе «Google Academia» на слова «anthocyanins and stability» обнаруживается более 37 тысяч ссылок на публикации. Но термин «устойчивость» применительно к антоцианам не является однозначным понятием. Это связано с тем, что антоцианы могут существовать в виде нескольких рН-зависимых форм [4], рис.1, различающихся окраской.

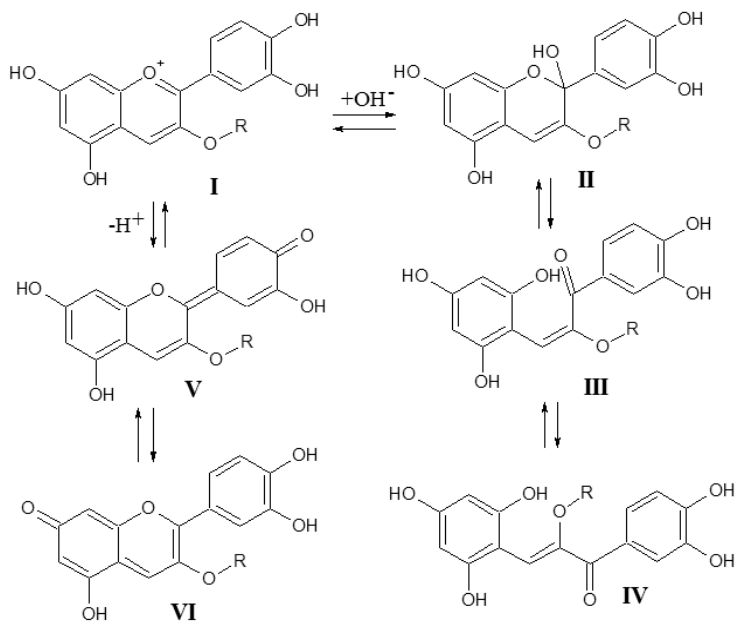

Рис. 1. Формы антоцианов в растворах

I - флавилиевая; II - псевдооснование (полукеталь); III - цүис-халкон; IV - трансхалкон; V и VI -хиноидные структуры

Окрашенная флавилиевая форма (I) при повышении рН (от 1 до 4.5) переходит в неокрашенную форму псевдооснования (II), что сопровождается обесцвечиванием растворов, но потерь антоцианов при этом нет - существует возможность возврата к изначальной флавилиевой форме после подкисления. Дальнейшее повышение $\mathrm{pH}$ приводит к окрашенным хиноидным формам (V и VI) также без формальной потери антоцианов. Отметим, что переходы между формами могут быть и не мгновенными (особенно это касается переходов в ряду II - III - IV [4]), что создает иллюзию нестабильности. При этом, разумеется, истинное разрушение основного каркаса молекулы возможно для любой из форм. Наконец, возможен гидролиз сложноэфирной связи с практически необратимым переходом от ацилированных антоцианов к неацилированным, что уже можно рассматривать как один из вариантов нестабильности.

Среди важных природных ацилирующих кислот можно отметить малоновую, определяющую существование цвиттерионных антоцианов [5], относительно которых известно, что они неустойчивы настолько, что не рекомендуется для их экстракции использовать подкисленный концентрированный раствор $\mathrm{HCl}$ (около 1\%) метанол [5]. Это на фоне утверждений об особой стабильности всех ацилированных антоцианов кажется довольно необычным.

Цель настоящей работы - установить стабильность ацилированных антоцианов относительно гидролиза сложноэфирных связей на примере малонированных производных.

\section{Эксперимент}

Антоцианы экстрагировали из высушенных лепестков оберток початков пурпурной кукурузы настаиванием в $0.1 \mathrm{M}$ водном растворе $\mathrm{HCl}$ при комнатной темпе- 
ратуре при периодическом перемешивании в течение 6 ч. Затем экстракт отделяли от твердого остатка фильтрованием через бумажный фильтр. Полученный экстракт для полупрепаративного выделения индивидуальных антоцианов очищали методом твердофазной экстракции на концентрирующих патронах ДИАПАК С18 (БиоХимМак СТ, Москва). Для этого концентрирующие патроны активировали, пропуская 5 мл ацетона, кондиционировали пропусканием $15 \mathrm{~cm}^{3} 0.1 \mathrm{M}$ водного раствора $\mathrm{HCl}$, антоцианы десорбировали экстратентом, содержащим 30 об.\% муравьиной кислоты и 30 об.\% ацетонитрила до обесцвечивания сорбента. Реэкстракт разбавляли в два раза дистиллированной водой. Такая процедура позволяла избавиться от полимерных соединений различных классов, способствуя длительной работе хроматографической колонки (в течение более 8 лет), но многие фенольные соединения (особенно фенольные кислоты) при этом из экстракта не удаляются.

Для определения антоцианов методом ВЭЖХ использовали хроматографическую систему Agilent 1260 Infinity с диодно-матричным детектором. Для регистрации хроматограммы использовали колонку $150 \times 4.61$ мм Symmetry C18, 3 мкм, температура термостата колонки $40^{\circ} \mathrm{C}$, состав подвижной фазы: 8 об.\% $\mathrm{CH}_{3} \mathrm{CN}, 10$ об.\% $\mathrm{HCOOH,} 82$ об.\% воды (0.8 мл/мин); хроматограмму записывали при 515 нм, хранили и обрабатывали, используя программу ChemStation 32.

Малонированные антоцианы выделяли полупрепаративно на хроматографе Shimadzu LC20 со спектрофотометрическим детектором (515 нм) на колонке $250 \times 10$ MM SUPELCO C18, 5 мкм при комнатной температуре с подвижной фазой 10 об. \% $\mathrm{CH}_{3} \mathrm{CN}, 10$ об. \% НСООН, 80 об. \% воды (5 мл/мин).

Образцы очищенных индивидуальных малонированных антоцианов при комнатной температуре, а другую порцию - в бытовом холодильнике $\left(4^{\circ} \mathrm{C}\right)$.

\section{Обсуждение результатов}

Несмотря на то, что для расщепления сложноэфирных связей в ацилированных антоцианах более эффективной является щелочная среда, в то время как гликозидные заместители удаляют кислотным гидролизом [6], про относительную неустойчивость в кислой среде малонированных антоцианов известно давно [5], но количественные характеристики этого процесса нами в литературе не были найдены.

Удобным объектом для исследования стабильности сложноэфирной связи в малонированных производных цианидина является антоциановый комплекс высушенных оберток пурпурной кукурузы [7]. В нем в относительно больших количествах содержатся три интересные в этом отношении соединения: один дималонат цианидин-3-(3",6"-дималонилглюкозид) (VII), и два мономалоната - цианидин-3-(6"малонилглюкозид) (VIII) и цианидин-3-(3"-малонилглюкозид) (IX). Стабильность этих соединений исследовали в элюенте при выдержке при комнатной температуре и при хранении в холодильнике $\left(4^{\circ} \mathrm{C}\right)$.

Различия в стабильности VII при двух использованных в работе температурах очевидны - по концентрации продуктов гидролиза, найденными методом обращенно-фазовой ВЭЖХ, рис.2.

По представленным на рис.2 данным очевидно, что превращение при хранении при $4^{\circ} \mathrm{C}$ протекает существенно медленнее, чем при комнатной температуре: доля продуктов гидролиза сложных эфиров значительно возрастает с ростом температуры (от 10.5 до 56.3 моль \% за 38 суток), более того, при комнатной температуре заметен и вторичный гидролиз - удаление второго радикала малоновой кислоты. Отметим, что концентрация цианидин-3-(6"-малонилглюкозида) оказывается всегда меньше концентрации цианидин-3-(3"-малонилглюкозида), что указывает на более 
легкий гидролиз сложноэфирной группы в положении 6-глюкозидного радикала по сравнению с положением 3.

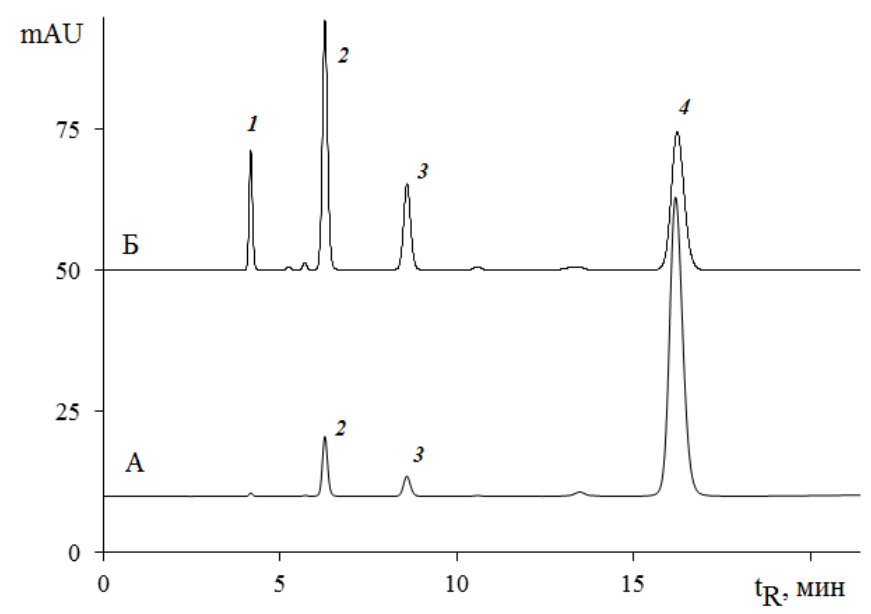

Рис. 2. Хроматограмма продуктов гидролиза цианидин-3-(3”,6”дималонилглюкозида)

Условия хранения; А - при $4^{\circ} \mathrm{C}$, Б - при комнатной температуре. Вещества: 1 - цианидин-3глюкозид, 2 - цианидин-3-(3"-малонилглюкозид), 3 - цианидин-3-(6"-малонилглюкозид), 4 - цианидин-3-(3",6"-дималонилглюкозид)

Константы скоростей гидролиза рассчитывали по площадям пиков веществ на хроматограммах, записанных через определенное время, оставляя растворы в автосамплере хроматографа при исследовании процесса при комнатной температуре. При этом, несмотря на отсутствие строго термостатирования, полученные результаты в целом соответствуют протеканию реакции гидролиза антоцианов по реакции первого порядка по антоцианам:

$$
\text { AcylA }+\mathrm{H}_{2} \mathrm{O} \rightarrow A+K,
$$

где AcylA исходный ацилированный антоциан, $A$ - продукт деацилирования; $K$ - кислота.

$$
\ln \frac{S(\text { AcylA })_{\tau}}{S(\text { AcylA })_{0}}=\ln \frac{[X]_{\tau}}{[X]_{0}}=k \cdot \tau
$$

где $\mathrm{S}$ - площади пиков на хроматограмме, пропорциональные $\mathrm{X}$ - концентрациям AcylA, при времени выдержки $\tau$ к площади пика на исходной хроматограмме, рис.3, $k$ - константа скорости реакции (сутки $\left.{ }^{-1}\right), \tau-$ время, сутки.

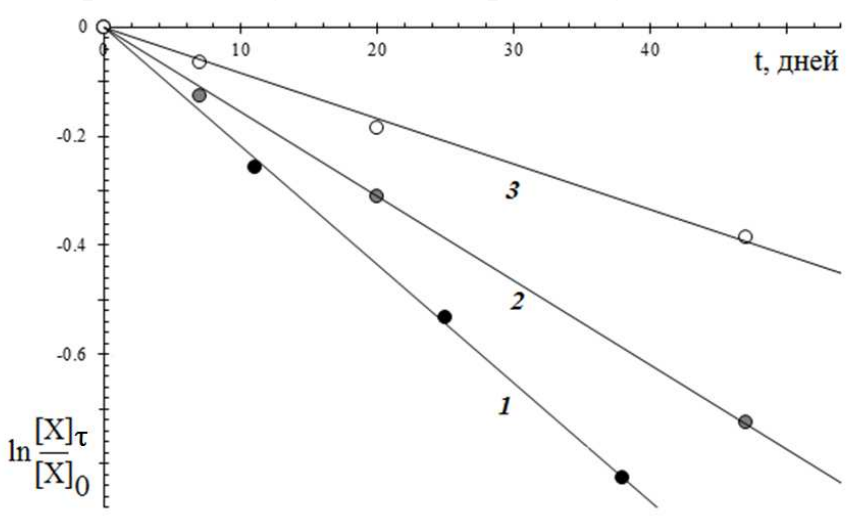

Рис. 3. Оценка скорости разрушения малонированных антоцианов по уравнению 1-го порядка

Антоцианы: 1 - цианидин-3-(3",6"-дималонилглюкозид), 2 - цианидин-3-(6"малонилглюкозид), 3 - цианидин-3-(3"-малонилглюкозид). Температура - комнатная $\left(23 \div 27^{\circ} \mathrm{C}\right)$. 
Так, при хранении при комнатной температуре константы скорости гидролиза соединений VII, VIII и IX составили $0.022 \pm 0.007,0.016 \pm 0.005$ и $0.008 \pm 0.003$, соответственно. По найденным константам можно подсчитать, что период полуразрушения антоцианов составит немногим более 30 , около 45 и почти 80 суток, соответственно. При хранении при $4^{\circ} \mathrm{C}$ период полуразрушения малонатов производных цианидин-3-глюкозида возрастает примерно в 5 раз.

\section{Заключение}

Особенность реакции гидролиза исследованных в работе малонированных антоцианов состоит в том, что: во-первых, сумма двух последних констант равна (в пределах погрешности эксперимента) первой константе, что свидетельствует о независимости гидролиза групп из различных положений. Во-вторых, удаление малоновой кислоты из положения 6" происходит примерно вдвое быстрее, чем из положения 3", что связано, скорее всего, с доступностью соответствующих радикалов. Таким образом, работа с малонированными антоцианами требует осторожности, но информация об их нестабильности заметно преувеличена. Поэтому выполнение качественного и количественного анализа антоциановых комплексов, включающих малонированные образцы, может быть осуществлено с высокой достоверностью с учетом найденных констант скоростей гидролиза радикалов малоновой кислоты.

\section{Список литературы}

1. Mónica Giusti M., Wrolstad R.E. // Biochem. Engineer. J. 2003. Vol. 14. pp. 217-225.

2. Bąkowska-Barczak A. // Pol. J. Food Nutr. Sci. 2005. Vol. 14/55. pp. 107-116.

3. Delgado-Vargas F., Jiménez A.R., ParedesLópez O. // Crit. Rev. Food Sci. Nutr. 2000. Vol. 40. pp. 173-289.

4. Pina F. // J. Chem. Soc., Faraday Trans. 1998. Vol. 94. pp. 2109-2116.

\section{References}

1. Mónica Giusti M., Wrolstad R.E., Biochem. Engineer. J., 2003, Vol. 14, pp. 217-225 http://doi.org/10.1016/S1369-703X(02)00221-8

2. Bąkowska-Barczak A., Pol. J. Food Nutr. Sci., 2005, Vol. 14/55, No 2, pp. 107-116, Available at https://www.google.ru/ url? $\mathrm{sa}=\mathrm{t} \& \mathrm{rct}=\mathrm{j} \& \mathrm{q}=\& \mathrm{esrc}=\mathrm{s} \&$ source $=\mathrm{web} \& \mathrm{~cd}=$ $1 \&$ ved=0ahUKEwjTwtergpfTAhVDApoKHRT wAXcQFggaMAA\&url=http $\% 3$

A\%2F\%2Fjournal.pan.olsztyn.pl\%2Ffd.php\%3 Ff\%3D507\&usg=AFQjCNFCR7OypIKiiDQIfI E 9d Q-

EzXUA\&sig2=n9IoQt1e9_Ve9cU1Ttoag\&bvm=bv.152174688,d.d24

3. Delgado-Vargas F., Jiménez A.R., ParedesLópez O., Crit. Rev. Food Sci. Nutr., 2000, Vol.
5. Harborne J.B., Boardley M. // Z. Naturforsch. 1985. Vol. 40c. pp. 305-308.

6. Moreno Y.S., Sánchez G.S., Hernández D.R., Lobato N.R. // J. Chromat. Sci. 2005. Vol. 43. pp. 483-487.

7. Дейнека В.И., Сидоров А.Н., Дейнека Л.А. // Журнал аналитической химии. 2016. T. 71. № 11. C. 1203-1208.
40(3), $\quad$ pp. 173-289

DOI:10.1080/10408690091189257.

4. Pina F., J. Chem. Soc., Faraday Trans., 1998, Vol. 94(15), pp. 2109-2116. DOI: 10.1039/A802602E Available at http://pubs.rsc.org/en/content/articlelanding/199 8/ft/a802602e\#!divAbstract

5. Harborne J.B., Boardley M., Z. Naturforsch., 1985, Vol. 40c, pp. 305-308 DOI: https://doi.org/10.1515/znc-1985-5-603. Available at https://www.degruyter.com/downloadpdf/j/znc. 1985.40.issue-5-6/znc-1985-5-603/znc-1985-5603.pdf

6. Moreno Y.S., Sánchez G.S., Hernández D.R., Lobato N.R., J. Chromatogr. Sci., 2005, Vol. 43, pp. 483-487. DOI: 
https://doi.org/10.1093/chromsci/43.9.483

Available at https://academic.oup.com/

chromsci/article/43/9/483/298251

/Characterization-of-Anthocyanin-Extracts-from

Дейнека Виктор Иванович - профессор кафедры общей химии, д.х.н., Белгородский государственный национальный исследовательский университет, Белгород

Сидоров Артем Николаевич - аспирант кафедры общей химии, Белгородский государственный национальный исследовательский университет, Белгород

До Ван Куи - магистрант кафедры общей химии, Белгородский государственный национальный исследовательский университет, Белгород

Дейнека Людмила Александровна - доцент кафедры общей химии, к.х.н., Белгородский государственный национальный исследовательский университет, Белгород
7. Deineka V.I., Sidorov A.N., Deineka L.A., J. Anal. Chem., 2016, Vol. 71, No 11, pp. 1145-1150. DOI: $10.1134 / \mathrm{S} 1061934816$ 110034 Available at https://link.springer.com/ article/10.1134/S1061934816110034

Deineka Victor I. - professor of Common Chemistry Chair of Institute of Engineering Technologies and Natural Sciences of Belgorod State National Research University. Dr. Sci. (Chemistry), email: deineka@bsu.edu.ru

Sidorov Artem N. - postgraduate of Common Chemistry Chair of Institute of Engineering Technologies and Natural Sciences of Belgorod State National Research University, e-mail: sidorov 31 @mail.ru

Do Van Quy - undergraduate of Common Chemistry Chair of Institute of Engineering Technologies and Natural Sciences of Belgorod State National Research University, e-mail: doquy93vp@gmail.com

Deineka Ludmila A. - professor assistant of Common Chemistry Chair of Institute of Engineering Technologies and Natural Sciences of Belgorod State National Research University. Ph.D. (Chemistry), e-mail: deyneka@bsu.edu.ru 